\title{
Migraine treatment: the race for the future is on
}

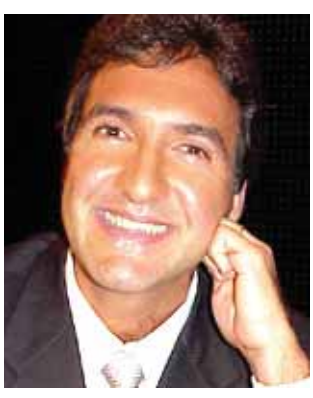

Abouch Valenty Krymchantowski

O ut-patient $\mathrm{H}$ eadache U nit Instituto de N eurologia

D eolindo Couto, Rua

Siqueira Campos 43/1002

Copacabana, Rio de Janeiro, 22031.070, Brazil

Tel.: +55 2122551055 ;

Fax: +55 212491 3657;

abouchkrym@globo.com

www.dordecabeca.com.br

\author{
'The race to fight migraine is on. \\ Various new molecular \\ pharmacological targets have \\ been identified, and the \\ development of strategies and \\ new drugs is c urrently under way.'
}

Knowledge regarding headaches, and particularly migraine, has been growing swiftly over the past two decades. Scientific, as well as clinical, progress has been enormous and new molecular pharmacological targets have emerged as this knowledge has been translated into clinical practice and through the elucidation of patients' needs. Although emerging drugs have shown more specific mechanisms of action, or at least our comprehension regarding the way drugs act on migraineurs' brains has become clearer, numerous patients reveal a nonresponding profile in contrast to their treatment expectations. In addition, physicians' expectations have not been fulfilled with available treatment strategies, despite the recent advances and aquisitions to the therapeutic arsenal.

Preventive medications as well as acute treatment agents require improvement with regard to outcome and tolerability issues, in order to provide greater improvement in quality of life and less suffering for the millions of migraineurs.

$\mathrm{H}$ owever, the way we see migraine and head pain has changed. Understanding the probable activation of nociceptors located at meningeal vessels followed by peripheral and central sensitization, combined with central pain processing and modulation disturbances (probably inherited genetically), has enlightened the efforts to fight migraine. In addition, neuronal hyperexcitability generated by an imbalance in glutamatergic-mediated excitation and gabaergic-mediated inhibition, also represents the basis for the comprehension of underlying mechanisms of migraine, which has directed the development of new molecular therapeutic targets both for prevention and acute intervention [1,2].
The biochemical elements of this conjunction of pathophysiological mechanisms have lead to the search for substances, their receptors and the way they are synthesized, released or suppressed. This means potential new drugs and new treatment paths.

Calcitonin generelated peptide (CGRP) and the substances related to its releasing mechanisms; neurokinin A, glutamate and $\gamma$-amino-butyric acid (GABA) receptors, adenosine $A 1$ receptors, nitric oxide synthase inhibitors, 5- $\mathrm{HT}_{1 \mathrm{D} / 1 \mathrm{~F}}$ receptors, vanilloid receptors, neuromodulation, as well as the modulation of various systems, such as the angiotensin system and many more, are the starting points for a new era in headache and migraine treatment. M oreover, combining current options and pharmacological agents, which may only act partially and reversibly on individual pathophysiological mechanisms, is also a potential improvement that will help obtain improved efficacy. Are we moving in the right direction?

The answer to this question is certain to be discovered in the near future of neurological science and medicine. However, insights from the basic science field as well as from clinical settings are encouraging. It seems that acute migraine therapies act on the initiation and perpetuation of neuronal mechanisms (such as trigeminal pathway activation and peripheral, as well as central, sensitization) in addition to modulating pain perception in peripheral and central nuclei. In contrast, the preventive effect of medications may be achieved through the elevation of the threshold for migraine activation inhibiting triggers and/or enhancing antinociceptive pathways at the periaqueductal gray [3].

This may lead to the following emerging paths, which will hopefully be successful:

- The combination of nonsteroidal anti-inflammatory drugs (N SAIDs) with a triptan seems to increase efficacy and counteract cutaneous allodynia, even in allodynic patients with severe headache $[4,5]$.

- The agonistic action on 5-HT $1 \mathrm{D} / 1 \mathrm{~F}$ receptors distributed on the neuronal elements of the trigeminal system seems to effectively abort a migraine attack without a limiting vasconstrictor effect on the coronary arteries [1]. 
- Inhibiting the release of CGRP which mediates trigeminal fibers, induces dilatation of cerebral vasculature, increased cerebral blood flow and trigeminal vascular reflex with potential CGRP antagonists, suggesting an uncoming path for blocking a developing migraine attack. CGRP is strongly associated with migraine, since its levels are elevated in migraineurs during an attack and it induces headache of the migrainous type in susceptible individuals $[6,7]$.

- The potent vasodilator and neuronal messenger nitric oxide, synthesized from L-arginine by three nitric oxide synthase isozymes, plays a crucial role in the migraine cascade [8]. The blocking effect of a specific nitric oxide synthase appears to be able to prevent, as well as impede the development of a migraine attack [9].

- Vanilloid receptors' agonism seems to release neurotransmitters to meningeal and dural blood vessels, with the resultant attenuation of neurogenic inflammation, peripheral sensitization and headache pain [10]. A possible reversal of an ongoing migraine attack may be achieved.

- The selective drug activation of adenosine A1 receptors may take part in nociceptive modula tion and attenuate the mechanism of central sensitization implicated in migraine. Adenosine Al receptors modulate chronic and acute pain in the spinal cord and are localized on cell bodies in the human trigeminal ganglia. In addition, the infusion of low doses of adenosine provides pain relief [11-13].

- Neuromodulators with certain multifaceted mechanisms of action, such as modern anticonvulsants, may provide better prophylactic efficacy outcomes, thereby reducing more intensively the frequency of migraine attacks. The possibility that a single agent may modulate glutamatergic and $\gamma$-aminobutyric acidergic transmission is very attractive and represents a potential, uninvestigated path for preventing migraine. In addition, some of these agents may also modulate voltage gated calcium channels such as the $P / Q$ calcium channels involved in neuronal activity that descend to the trigeminal nucleus caudalis. This action on modulating specific ion channels promoted by these pharmacological agents is capable of inhibiting CGRP release [14,15].

- Angiotensin system modulators which may reduce glutamate release and enhance gabaergic inhibitory tone have demonstrated effective prophylactic activity in migraine. Probable mechanisms of these emerging preventive agents are the possible blockade in the conversion of angiotensin I to angiotensin II, as well as blocking the degradation of substance $P$, enkephalin and bradykinin, along with the increase of prostacyclin synthesis $[16,17]$.
'Preventative medications as well as ac ute treatment agents require improvment with regard to outc omes and tolera bility issues...'

The race to fight migraine is on. Various new molecular pharmacological targets have been identified, and the development of strategies and new drugs is currently under way. The possible development of more predictive clinical pharmacological models in humans, the identification of disease biomarkers, as well as refining methods for specific drug development are desired. In addition, new insights from the scientific knowledge of migraine mechanisms have improved our methods of choosing directions in which to search for new treatments. D rug synergies targeting more than one mechanism simultaneously, avoiding disease progression with action on factors supposedly involved in fighting and reversing the early stages of acute attacks and its pathophysiological substrates will certainly be the focus of our future as headache and migraine clinicians and researchers. Let's move on!
Bibliography

1. Waeber C, M oskowitz M A: Therapeutic implications of central and peripheral mechanisms in migraine. N eurology 61(8 Suppl. 4), S9-S20 (2003).

2. Ward TN, Levin M : D iagnosis and pathophysiology of migraine. Expert Rev. N eurotherapeutics 4(3), 383-390 (2004).

3. Buchanan TM, Ramadan N M , Aurora S: Future pharmacologic targets for acute and preventive treatments of migraine. Expert Rev. N eurotherapeutics 4(3), 391-430 (2004).

4. Jabukowski M, Levy D, Goor-Aryeh I, Collins B, Bajwa Z, Burstein R:

Terminating migraine with allodynia and ongoing central sensitization using parenteral administration of COX1/COX2 inhibitors. H eadache 45, 766 (2005) (Abstract).
5. Krymchantowski AV, Bigal ME: Rizatriptan versus rizatriptan plus rofecoxib versus rizatriptan plus tolfenamic acid in the acute treatment of migraine. BM C N eurol. 28(4), 10-15 (2004).

6. Edvinsson L, M ulder H, G oadsby PJ, Uddman R: Calcitonin generelated peptide (CGRP) and nitric oxide in the trigeminal ganglion: cerebral vasodilatation from trigeminal nerve stimulation involves 
mainly CGRP. J. Auton. N erv. Syst. 70(1), 15-22 (1998).

7. Lassen LH, H aderslev PA, Jacobsen VB, Iversen HK, Sperling B, O lesen J: CGRP may play a causative role in migraine. Cephalalgia 22(1), 54-61 (2002).

8. Thomsen LL, O lesen J: Nitric oxide theory of migraine. Clinical N eurosci. 5(1), 28-33 (1998).

9. Lassen LH , Christiansen I, I versen H K, Jansen-O lesen I, O lesen J: The effect of nitric oxide synthase inhibition on histamine-induced headache and arterial dilatation in migraineurs. Cephalalgia 23(9), 877-886 (2003).

10. Diamond S, Freitag F, Phillips S, Bernstein J, Saper J: Intranasal civamide for the acute treatment of migraine headache. Cephalalgia 20(6), 597-602 (2000).

11. Schindler $M, H$ arris $C A, H$ ayes $B$, Pappoti M , H umphrey PPA: Immunohistochemical localization of adenosine $A 1$ receptors in human brain regions. N eurosci. Letter 297(Suppl. 3), 211-215 (2001).

12. Sollevi A, Belfrage $M$, Lundeberg $T$, Segerdahl M , H ansson P: Systemic adenosine infusion: a new treatment modality to alleviate neurophathic pain. Pain 61(1), 155-158 (1995).

13. Burstien $\mathrm{R}$, Jabukowski $\mathrm{M}$ : Analgesic triptan action in an animal model of intracranial pain: a race against the development of central sensitization. Ann. N eurol. 55(1), 27-36 (2004).

14. Akerman S, W illiamson DJ, G oadsby PJ: Voltage-dependent calcium channels are involved in neurogenic dural vasodilatation via a presynaptic transmitter release mechanism. Br. J. Pharmacol. 140(3), 558-566 (2003).

15. Wallace $M \mathrm{~S}: \mathrm{C}$ alcium and sodium channel antagonists for the treatment of pain. J. Pain 16 (Suppl. 2), S80-S85 (2000).
16. Tronvik E, Stovner LJ, H elde G, Sand T, Bovin G: Prophylactic treatment of migraine with an angiotensin II receptor blocker: a randomized controlled trial. JAM A 289(1), 65-69 (2003).

17. Schrader H, Stovner LJ, H elde G, Sand T, Bovin G: Prophylactic treatment of migraine with angiotensin converting enzyme inhibitor (lisinopril): randomized, placebo-controlled cross-over study. Br. M ed. J. 322(7277), 19-22 (2001).

\section{Affiliations}

- Abouch Valenty Krymchantowski, M D, M Sc, PhD, FAHS

O ut-patient $\mathrm{H}$ eadache U nit, Instituto de N eurologia D eolindo C outo, Rua Siqueira Campos 43/1002 Copacabana, Rio de Janeiro, 22031.070, Brazil

Tel.: +55 212255 1055;

Fax: +55 212491 3657;

abouchkrym@globo.com

www.dordecabeca.com.br 